\title{
Coexisting Social, Economic, and Health-Related Disadvantages in More than 2.4 Million Swedes: Combining Variable-Centred and Person-Centred Approaches
}

\author{
Stefan Fors ${ }^{1} \mathbb{D} \cdot$ Ylva B. Almquist $^{2} \mathbb{D} \cdot$ Lars Brännström $^{3} \mathbb{D}$
}

Accepted: 4 August 2018 / Published online: 14 August 2018

(c) The Author(s) 2018

\begin{abstract}
The notion of coexisting disadvantages has been recognised in social welfare policy and welfare research, not least in the Nordic countries. The prevalence and patterning of coexisting disadvantages in society have far reaching implications for well-being, social policy, and social inequality. Using longitudinal register-based data for the years 1998-2008 for all Swedish individuals born 1946-1965 ( $\mathrm{n}>2.4$ million), this exploratory study maps out the occurrence of coexisting disadvantages in the Swedish working-age population, and examines to what extent observed prevalence rates are associated with sex, age, immigrant status, and marital status. Coexisting disadvantages are analysed in terms of four broad register-based indicators intended to capture individuals' resources in key areas of the society: education, income, labour market, and mental health. The results show that while most individuals are not disadvantaged in these areas, coexisting disadvantages do occur and its prevalence varies according to sex, age, immigrant status, and marital status. This study shows that combinations of person-centred and variable-centred analyses of register-based indicators can play a part when developing effective systems for policy surveillance.
\end{abstract}

Keywords Latent class analysis · Monitoring $\cdot$ Person-centred methods $\cdot$ Register data Social exclusion $\cdot$ Welfare problems

\section{Introduction}

In Sweden, as in other countries, issues of poverty, social exclusion, and the improvement of living conditions remain at the very core of social welfare research and the policy agenda (European Commission 2010; Tsakloglou and Papadopoulos 2002). As

Stefan Fors

stefan.fors@ki.se

1 Aging Research Center, Karolinska Institutet and Stockholm University, 17177 Stockholm, Sweden

2 Department of Public Health Sciences, Centre for Health Equity Studies (CHESS), Stockholm University, 10691 Stockholm, Sweden

3 Department of Social Work, Stockholm University, 10691 Stockholm, Sweden 
a consequence, much contemporary research concerns the prevalence, distribution, and time trends of disadvantages within, and across, societies.

Yet, how disadvantages are best assessed remain a key question in the social sciences. While single domain indicators, often financial (e.g., poverty), regularly serve as indices of disadvantage, several calls have been made for a multidimensional approach to social welfare in general (Stiglitz et al. 2010) and to disadvantages in particular (Esping-Andersen and Unies 2000). In this study, we will analyze disadvantages from a multidimensional perspective by focusing on the co-occurrence of disadvantages among individuals. Throughout the study, we will use the term coexisting disadvantages (Heap et al. 2013) to denote the simultaneous experience of two or more disadvantages.

There are essentially three types of mechanisms that may lead to coexisting disadvantages. First, there is coincidence. Even in a situation where disadvantages are randomly distributed, some individuals will be unlucky enough to be bestowed with two or more simultaneous disadvantages, if only the population is large enough. That is, coexisting disadvantages will occur occasionally even when there are no association between the disadvantages. However, there is strong evidence showing that the risks of different types of disadvantages tend to be associated. This observation leads us to the second type of mechanism, where coexisting disadvantages emerge as a consequence of causal relationships between the disadvantages (e.g., mental illness increase the risk of unemployment, and vice versa). Finally, coexisting disadvantages may also occur because certain individuals or groups in the population (e.g., due to discrimination, social class, poverty, limited cognitive or non-cognitive abilities, lack of social capital), simultaneously and independently, are at increased risk of several different disadvantages. In reality, these mechanisms are not mutually exclusive and it is likely that all three types of mechanisms contribute to the prevalence and patterning of coexisting disadvantages in the population. Yet, their relative contributions may differ between populations and over time.

There are good reasons to continuously monitor and analyze the occurrence of coexisting disadvantages within the population. Individuals who experience simultaneous disadvantages, across different life domains are likely to have a decreased quality of life, and may find it difficult to manage the challenges of everyday life. Hence, they constitute a group that is a key target for social welfare policy and practice. In a report written for the United Nations, the authors stated that "society's most pressing welfare problems will always be where hardship or resource weakness cumulate" (Esping-Andersen and Unies 2000).

Where individuals who experience coexisting disadvantages are excluded from several of the areas that determine social integration in society, it is also related to the concept of social exclusion (Halleröd and Bask 2008). While there is still no consensual, definitive definition of social exclusion (Whelan and Maître 2005), most would probably agree that it refers to a dynamic and complex process that, partially or fully, excludes individuals or groups of individuals from participating in the social, economic, political, or cultural spheres of society.

Besides contributing to a nuanced perspective on the occurrence of disadvantages in a given society, a multidimensional approach to disadvantage can also contribute to realistic estimates of the overall inequalities (Fritzell and Lundberg 2000) and inform discussions on distributive justice. To the extent that different types of disadvantages cluster and aggregate among certain individuals, or groups of individuals, this may suggest that the distribution of resources across different spheres of society is dominated by the same underlying principles, something which arguably constitute an injustice or inequity (Walzer 1983). 
The aim of this study is twofold: (i) to map out the prevalence of different configurations of disadvantages in the working-age population in Sweden during the period 1998-2008, and (ii) to analyze whether the prevalence varies by sex, age, immigrant status, and marital status.

We will address these aims using longitudinal register-based data for the years 1998-2008, for all Swedish individuals born 1946-1965 ( $\mathrm{n}>2.4$ million). We will estimate the prevalence of coexisting disadvantages in terms of four broad register-based indicators intended to capture disadvantages in key areas of the society: education, income, labour market, and mental health.

Previous research has shown that the likelihood of disadvantages is unevenly distributed in the Swedish population. Age, gender, immigrant status, and marital status are all associated with disparities in the likelihood of disadvantages. In Sweden, the expansion of the educational system has led to increased levels of educational attainment in each new birth cohort, and particularly so among women. Among immigrants, the average educational attainment varies substantially depending on the country of origin (Statistics Sweden 2014a).

With regard to labour market outcomes, men have somewhat higher unemployment rates compared to women (Statistics Sweden 2014b). Similarly, immigrants have substantially higher average rates of unemployment than native born Swedes (Eriksson 2011). Regarding income-related disadvantages, the rates of social assistance receipt is overall higher among men than women, among immigrants than among native born Swedes, and tends to become lower with age (Statistics Sweden 2016; The National Board of Health and Welfare 2013). These gender differences are, however, mainly restricted to young adulthood, while the largest proportion of social assistance recipients is found in single-mother households (Statistics Sweden 2014b).

Poor mental health-here reflected by diagnoses related to e.g. anxiety, depression, alcohol abuse, and drug abuse - is more common among men (caused by their higher prevalence of alcohol and drug abuse) and, for men and women alike, peaks around ages 50-54 and then drops (The National Board of Health and Welfare 2016). Poor mental health is also less common among married/cohabiting adults, than among those who are unmarried, divorced/separated, or widowed (Lindström and Rosvall 2012). Mental health problems are also more common among immigrants than among native born Swedes (Gilliver et al. 2014).

Overall, the observed heterogeneity for each indicator implies that gender, age, immigrant status, and marital status may be relevant to analyse also in relation to the prevalence of coexisting disadvantages. However, we make no a priori hypotheses with regard to any such differences.

Previous studies of coexisting disadvantages can roughly be divided into two categories, based on their study design: variable-centered studies and person-centered studies.

The bulk of the research on coexisting disadvantages have been based on variable-centered analyses. Variable-centred analyses are used to analyse the associations between variables in a given population. A common variable-centred approach to coexisting disadvantages has been to calculate the quantity of disadvantage, i.e. the absolute number of disadvantages that each individual is exposed to (e.g. Bask 2016; Butterworth 2003; Ferrarini et al. 2010; Fritzell et al. 2007; Fritzell and Lundberg 2000; Korpi et al. 2007). For example, Korpi et al. (2007) based their analysis on a representative, random sample of the Swedish population, and included seven indicators of disadvantage: unemployment; no cash margin; ill-health; deficient citizenship skills; inadequate social network; insecure housing situation; and inadequate personal security. Based on 
these indicators, a measure (calculated separately for the survey data collected in 1974, 1981, 1991, and 2000) was constructed, indicating the total number of disadvantages. The results showed that, on average, about $10 \%$ of the population reported coexisting disadvantages (i.e. at least two disadvantages) during the period 1974-2000. During the study period, the proportion of individuals reporting coexisting disadvantages decreased between 1974 and 1991, followed by an increase in 2000. The probability of reporting coexisting disadvantages was generally higher among women (albeit, only in 1974 and 1981), people born outside Sweden, single people without children, manual workers, and young adults. Furthermore, lack of a cash margin was the disadvantage most strongly linked to the other types of disadvantage: $60-70 \%$ of those who experienced coexisting disadvantages had no cash margin.

Measuring coexisting disadvantages in this way is a straight-forward approach that makes it rather easy to analyse changes over time and compare differences between groups. Nevertheless, it has some drawbacks. First of all, it requires a predefined cut-off point between what constitutes a disadvantage and what does not. The simple count of disadvantages moreover assumes that all disadvantages are of equal importance for the individual's living situation: for example, sleeping problems would be assigned the same weight as unemployment. This approach may also fail to recognise the importance of specific combinations of disadvantage: among individuals with coexisting disadvantages, some combinations may be more common - and/or more meaningful - than others.

An alternative, but less common, variable-centred strategy has been to focus on specific combinations of disadvantage derived from theory or from the manifest structure of the data (Danziger et al. 2000). For instance, in a study based on a nationally representative sample of Swedes, five types of disadvantage were considered: physical health problems, psychological health problems, low frequency of social contacts, lack of economic resources, and lack of political resources (Heap et al. 2013). The authors also examined which combinations of disadvantage had the highest prevalence. For both sexes and across all age groups, the most common combinations involved psychological health problems. While this approach may deepen our knowledge about the disadvantages that actually coexist in the population under study, it too requires that a cut-off point between advantage and disadvantage is predefined. Moreover, it is often impractical to identify all possible combinations especially if a large number of disadvantages are investigated.

Person-centered studies, on the other hand, make up a minor but growing portion of the studies of coexisting disadvantages. Person-centered analyses are used to explore the associations between variables within individuals (Muthen and Muthen 2000). One way of addressing coexisting disadvantages with a person-centered approach, is through the use of latent class analysis (LCA) (e.g. Almquist 2015; Almquist and Brännström 2013, 2014; Bask 2011; Halleröd and Larsson 2008). LCA is a data-driven method that indentifies clusters of individuals, characterised by similar patterns of disadvantages, within a given population (Masyn 2013). Halleröd and Larsson (2008) examined the clustering of eight indicators of disadvantage (reflecting unemployment, economic vulnerability, health problems, loneliness, and anxiety) by applying LCA to data from the Swedish Survey of Living Conditions (ULF) in 1998. They identified three clusters: $71 \%$ of the individuals ended up in a cluster characterised by low probabilities of having any of the disadvantages; $19 \%$ belonged to a cluster largely determined by the different types of health-related problems; and about $10 \%$ of the individuals were located in a cluster characterised by high scores on all eight of the disadvantages. Those with the lowest risk of ending up in any of the two latter clusters were men, individuals from the higher social classes, and cohabiting people with children. 
In this study, we will utilize both person-centered and variable-centered analyses to address our aims. As a first step, we will use a person-centered analysis (i.e., LCA) to identify clusters of individuals, characterized by different configurations of disadvantages, in the population. As the second step, we will then use variable-centered analysis (i.e., multinomial regression) to estimate differences in the likelihood of belonging to the different clusters by sex, age, immigrant status, and marital status. This analytic strategy will allow us to map out the social landscape of real-world groups of individuals, with different patterns of disadvantages, rather than to test the validity of pre-defined hypothetical combinations of disadvantages in the population. Moreover, it will allow us to test whether the probability of being in these groups are contingent on a range of sociodemographic features.

\section{Data and Methods}

The study is based on the Swedish Work and Mortality Database (WMD) which is an anonymous, temporary database created in 2003. Its establishment was approved by the Regional Ethics Committee at Karolinska Institutet (no. 02-481), whereas permissions for later extensions of the WMD have been received from the Stockholm Regional Ethics Committee (no. 04-628T; 2008/1991-32). The WMD includes all individuals born before 1985 who were alive and resident in Sweden in 1980 and/or 1990. A variety of national registers have been linked to the WMD. The current study used information about social, economic, and health-related measures derived from the WMD for the years 1998-2008. Moreover, the study was restricted to individuals born between 1948 and 1968 (i.e., ages 30-50 in 1998; ages 40-60 in 2008). The lower age limit was chosen in order to ensure that the educational level had been finalised for as many as possible whereas the upper age limit was set in order to exclude those who were at or near the age of retirement. In 1998 this age segment accounted for $29 \%$ of the Swedish population (Statistics Sweden 2018). The WMD consisted of 2,775,837 individuals born between 1948 and 1968. Approximately $88 \%$ had information about disadvantages in 1998-2008 $(n=2,439,896)$. Missing data were slightly more common among men compared to women, among those not married, as well as among those with immigrant background, whereas no differences according to birth year were detected.

\subsection{Variables}

As shown in Table 1, the study sample contained an equal share of men and women. Based on information about birth year, the following categories reflecting age in 1998 were constructed: 'Age 30-35', 'Age 36-40', 'Age 41-45', and 'Age 46-50'. Immigrant status was, for reasons of data availability, defined as having migrated to Sweden during the period 1990-1997. Marital status was measured in 1997. About half the sample were married at that time, almost $40 \%$ were unmarried, and the rest were divorced, widowed or unclassified.

We began by constructing four ordinal variables from the available register data, all reflecting individuals' disadvantages in key areas of the society (1998-2008): education, income, labour market, and mental health (Table 1). The first three indicators were derived from the Longitudinal Integration Database for Health Insurance and Labour Market Studies (LISA by Swedish acronym) whereas information about mental health problems was derived from the Hospital Discharge Register. 
Table 1 Sample properties: descriptive statistics $(\mathrm{n}=2,439,896)$

\begin{tabular}{|c|c|c|}
\hline Variables & Definition & Percent \\
\hline \multirow[t]{3}{*}{ Gender } & Sex & \\
\hline & Man & 50.5 \\
\hline & Woman & 49.5 \\
\hline \multirow[t]{5}{*}{ Age } & Age group & \\
\hline & Age $30-35$ & 30.5 \\
\hline & Age 36-40 & 22.8 \\
\hline & Age 41-45 & 23.0 \\
\hline & Age $46-50$ & 23.8 \\
\hline \multirow[t]{3}{*}{ Immigrant status } & Immigrant status & \\
\hline & No & 94.6 \\
\hline & Yes & 5.4 \\
\hline \multirow[t]{6}{*}{ Marital status } & Marital status & \\
\hline & Married & 50.9 \\
\hline & Unmarried & 37.8 \\
\hline & Divorced & 10.4 \\
\hline & Widow/widower & 0.5 \\
\hline & Unclassified & 0.5 \\
\hline \multirow[t]{4}{*}{ Education } & Educational attainment & \\
\hline & Compulsory & 33.6 \\
\hline & Upper secondary & 50.0 \\
\hline & University & 16.5 \\
\hline \multirow[t]{4}{*}{ Economic hardship } & Social welfare receipt & \\
\hline & 0 years & 84.8 \\
\hline & $1-2$ years & 8.2 \\
\hline & 3 or more years & 7.0 \\
\hline \multirow[t]{4}{*}{ Labor market participation } & Unemployment & \\
\hline & 0 years & 66.2 \\
\hline & $1-2$ years & 15.9 \\
\hline & 3 or more years & 18.0 \\
\hline \multirow[t]{4}{*}{ Mental health } & Mental health problems & \\
\hline & 0 discharges & 96.3 \\
\hline & 1-2 discharges & 2.4 \\
\hline & 3 or more discharges & 1.4 \\
\hline
\end{tabular}

Education, here understood as educational attainment, reflects highest educational level. Information about educational attainment was collapsed into the following categories: 'Compulsory', 'Upper secondary', and 'University'. To the extent a knowledgebased economy yields a focus on educational achievements (Schleicher 2007), and education reflects people's ability to participate effectively in economic, social, and cultural life (Duffy 1995), lower levels of educational attainment can be seen as a marker for disadvantage (Klasen 2001).

Financial hardship-here conceptualised as having received means-tested social welfare-is a clear indication that a person has limited economic discretion. Information about means-tested social welfare receipt concerns the yearly amount of benefit 
expressed in hundreds of Swedish crowns. This information was coded into the number of years in 1998-2008 during which the individual at any time received social welfare, and subsequently categorised into ' 0 years', ' $1-2$ years', and ' 3 or more years'.

The labour market is undeniably of utmost importance for people's welfare. Apart from the fact that a job brings with it an income which increases the likelihood of being able to live a decent life, it also gives a structure to one's daily existence. While there are many reasons why someone may not have a job (e.g., long-term sick leave, parental leave), unemployment is one of the most common. The studied indicator of disadvantage at the labour market are based on the number of days in full-time unemployment during a year. This information was coded into the number of years in 1998-2008 during which the individual was, at any time, unemployed, and subsequently categorised into ' 0 years', '1-2 years', and '3 or more years'.

Mental health referred to mental health problems and concerned discharges from the hospital in 1998-2008 according to Chapter F in the International Classification of Diseases: 'Mental and behavioural disorders'. This chapter includes diagnoses related to e.g. depression, anxiety, and alcohol and drug abuse. In the current study sample, the prevalence on the latter two diagnoses was much higher in comparison to the former two. Here, three categories were created: '0 discharges', '1-2 discharges', and '3 or more discharges'. Due to lack of discharge data, any hospital stays that were still ongoing at the time when the study period ended (i.e., beyond 2008-12-31) are not recorded in the variable.

\subsection{Statistical Analysis}

We applied LCA, using Mplus 7.2, to reduce the number of combinations (four ordinal variables ranging from 1 to 3 would yield $3^{4}=81$ possible alternatives) and thereby identify relevant clusters of individuals characterised by similar profiles. While it is an intricate task to decide on the final number of clusters, it can be assisted by the evaluation of various types of model fit statistics. In this study, we assessed five measures of model fit to decide on the number of clusters: Bayesian Information Criterion (BIC), entropy, bivariate residual correlation, the Vuong-Lo-Mendell-Rubin likelihood ratio test, and the occurrence of empty clusters.

BIC assesses the relative goodness of fit, where lower values relative to the other models correspond to better fit (Kuha 2004). BIC weights both model fit and parsimony and tends to favour simpler models in very large datasets, thereby reducing the risk of over-fitting (Raftery 1995). Since the sample size was exceedingly large in the current study, we opted for samplesize adjusted BIC. Entropy is a measure of the quality of classification, ranging between 0 and 1, where a higher score reflects better classification. Examining the correlation between the bivariate residuals is a test of the local independence assumption: if these residuals are uncorrelated it means that the manifest variables are independent of each other within the latent classes. The bivariate residuals tend to become less correlated as the model gets more complex. The Vuong-Lo-Mendell-Rubin likelihood ratio test compares the more complex model to the simpler model: if $p<0.05$, the more complex model fits the data better.

It should be pointed out that these types of statistics may identify different models as having the best fit. Moreover, while more complex models usually fit the data better, they tend to provide cluster solutions with less intuitive meaning (Nylund et al. 2007). Therefore, we included a fifth indicator of model fit, reflecting whether or not all predicted clusters contained individuals. Each individual's cluster membership is based upon which cluster he or she has the highest probability score of belonging to. In other words, while the 
estimated model may identify a certain number of clusters in the data, it could happen that for one (or more) of the clusters, the probabilities are lower compared to the others clusters and, thus, no individual would be assigned to that specific cluster.

Based on the model fit statistics reported in Table 2, the seven-cluster solution had the lowest values for BIC, followed by the eight-cluster solution. While the eight-cluster solution had higher entropy compared with the seven-cluster solution, the former did not provide a significantly better fit to the data. Therefore, we chose to proceed with the sevencluster solution despite a few instances of correlated bivariate residuals (only 2 out of 54 $\mathrm{z}$-scores were above 1.96 whereas the remaining scores were well below). It should also be noted that the modification indices did not show that any significant improvement of model fit would be reached if direct effects between the indicators had been included.

To assess whether cluster membership differed depending on sex, age group, immigrant status, and marital status, we used a multinomial regression analysis. For ease of interpretation, we used relative risk ratios (RRR) as effect size. All regressions were estimated using Stata 13/SE-version (Long and Freese 2006).

\section{Results}

Figure 1 reports the distribution (based on z-scores) of educational attainment, social assistance receipt, unemployment, and mental health problems for each of the seven clusters. The labelling of clusters has been made using one standard deviation from the mean (i.e., -1 or 1 ) as the cut-off point (the estimated probabilities for the different levels/thresholds of the four indicators are shown in Fig. 2a-c in 'Appendix'). The largest cluster contained $66.4 \%(n=1,620,624)$ of the individuals and was characterised by average levels of educational attainment, social welfare receipt, unemployment, and mental health problems ('Average'). Approximately $21.6 \%(n=528,063)$ were found in the second largest cluster which was characterised by comparably more unemployment (' $U$ '). The third cluster consisted of $0.3 \%(n=7140)$ of the individuals and was identified as having comparably less educational attainment and more mental health problems ('eM'). Approximately 5.1\% $(n=123,096)$ of the individuals were located in the fourth cluster, characterised by comparably more social welfare receipt and unemployment ('SU'). Around $2.5 \%(\mathrm{n}=59,674)$ of the individuals

Table 2 LCA model fit statistics $(\mathrm{n}=2,439,896)$

\begin{tabular}{llllll}
\hline $\begin{array}{l}\text { Number of } \\
\text { classes/clus- } \\
\text { ters }\end{array}$ & $\begin{array}{l}\text { Sample-size adjusted } \\
\text { BIC }\end{array}$ & $\begin{array}{l}\text { Entropy/quality } \\
\text { of classification }\end{array}$ & $\begin{array}{l}\text { Uncorrelated } \\
\text { bivariate } \\
\text { residuals }\end{array}$ & Likelihood ratio test & $\begin{array}{l}\text { Empty } \\
\text { cluster(s) }\end{array}$ \\
\hline 1 & $12,679,945.865$ & 1.00 & No & - & - \\
2 & $12,330,426.895$ & 0.81 & No & $p<0.000$ & No \\
3 & $12,310,715.156$ & 0.75 & No & $p<0.000$ & No \\
4 & $12,299,280.652$ & 0.61 & No & $p<0.000$ & No \\
5 & $12,297,940.885$ & 0.61 & No & $p<0.000$ & No \\
6 & $12,297,448.409$ & 0.63 & No & $p<0.000$ & No \\
$7^{\text {a }}$ & $12,297,341.869$ & 0.74 & No & $p<0.000$ & No \\
8 & $12,297,371.691$ & 0.73 & No & $p>0.050$ & No \\
\hline
\end{tabular}

LCA latent class analysis, BIC Bayesian information criterion

${ }^{\text {a}}$ Preferred model 


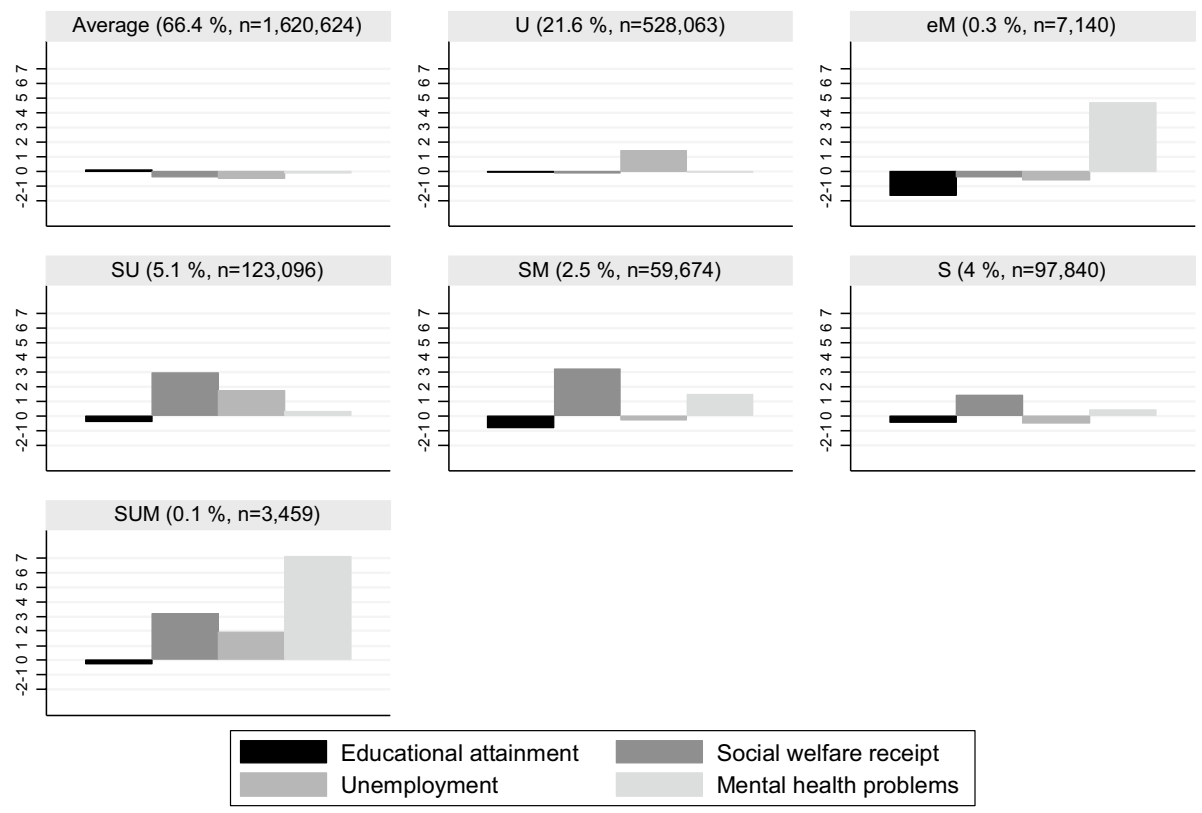

Fig. 1 Clusters of disadvantage $(n=2,439,896)$. Note: Bars represent $z$-scores of educational attainment, social welfare receipt, unemployment, and mental health problems. Labeling of clusters is based on one standard deviation from the mean (i.e., -1 and 1) as the cut-off point

were in the fifth cluster characterised by comparably more social welfare receipt and mental health problems ('SM'), whereas $4 \%$ were located in a cluster characterised by comparably more social welfare receipt ('S'). Finally, $0.1 \%(n=3459)$ of the population were found in a cluster with comparably more social welfare receipt, unemployment, and mental health problems ('SUM'). Based on our person-centred approach (and specific labelling), 7.9\% $(n=193,369)$ of the individuals were identified as having various forms of coexisting disadvantages (i.e. clusters 'eM', 'SU', 'SM', and 'SUM').

Table 3 demonstrates differences in the probabilities of cluster membership according to sex, age group, immigrant status, and marital status in a mutually adjusted model. Compared to men, women had a $27 \%$ elevated risk $(\mathrm{RRR}=1.27)$ of being in the cluster characterised by higher levels of social welfare receipt ('S') rather than in the 'Average' cluster. Moreover, women had $44 \%$ elevated risk $(\mathrm{RRR}=1.44)$ of being in the cluster characterised by higher levels of social welfare receipt and mental health problems ('SM'). Women also had a statistically significantly elevated risk $(R R R=1.15)$ of ending up in the cluster characterised by comparably more unemployment ('U'). Conversely, women had a lower risk of ending up in the cluster characterised by comparably less education and higher levels of mental health problems ('eM', RRR $=0.75$ ). Moreover, they had a slightly lower risk $(R R R=0.97)$ of being in the cluster characterised by more social welfare receipt and unemployment ('SU'). Finally, they had a 52\% lower risk $(\mathrm{RRR}=0.48)$ of simultaneously having more social welfare receipt, unemployment and mental health problems ('SUM').

We found a negative association between age and the likelihood of ending up in the clusters characterised by higher levels of unemployment ('U'), more social welfare receipt and unemployment ('SU'), and more social welfare receipt, unemployment and mental health problems cluster ('SUM'). That is, older individuals were at lower risk of being in 
these clusters rather than in the 'Average' cluster, compared to the younger individuals. Conversely, we found a positive association between age and the likelihood of being in the cluster characterised by comparably less education and more mental health problems ('eM'), indicating that older individuals, on average, had less education. Older individuals also had elevated risks of being in the clusters characterised by higher levels of social welfare receipt and mental health problems ('SM'), and more social welfare receipt ('S').

Individuals with immigrant status were more likely, than those without immigrant status, to belong to the clusters characterized by unemployment (' $U$ '), social welfare receipt and unemployment ('SU'), social welfare receipt and mental health problems ('SM'), social welfare receipt ('S'), and social welfare receipt, unemployment and mental health problems ('SUM'), rather than the 'Average' cluster. These associations were exceptionally strong for the clusters 'SU' $(R R R=20.1)$ and 'SM' $(R R R=12.7)$.

In terms of marital status, those who were unmarried, divorced or widowed were more likely than those who were married to belong to all other clusters than the 'Average' cluster. The largest differences were observed among the divorced and the widowed in the likelihood of belonging to the cluster characterised by higher levels of social welfare recipiency, unemployment, and mental health problems ('SUM'). Those who were unclassified were less likely than the married to belong to the clusters characterized by unemployment (' $U$ '; RRR =0.75), and social welfare recipiency ('S'; RRR =0.64) rather than the 'Average' cluster, but more likely to be in all other clusters.

\section{Discussion and Conclusions}

By applying LCA to a database containing longitudinal information from administrative registries for more than 2.4 million Swedes, we were able to identify seven different clusters of individuals, characterized by different configurations of disadvantages. The majority of the sample $(66.4 \%)$ belonged to a cluster characterised by little or no disadvantages. Among those who belonged to clusters characterized by higher levels of disadvantages, most (25.7\% of the sample) belonged to clusters characterized by increased levels of a single disadvantage. Out of the seven clusters, three (encompassing about $7.9 \%$ of the sample) were characterised by two or three coexisting disadvantages.

We also found that there were substantial differences in the probability of belonging to different clusters, depending on sex, age, immigrant status, and marital status. Women had significantly higher risks of ending up in the clusters characterised by comparably more social welfare receipt ('S') as well as more social welfare receipt and mental health problems ('SM'). However, they had lower risks of ending up in clusters characterised by relatively less education and more mental health problems ('eM'), combinations of social welfare receipt and unemployment ('SU'), as well as combinations of social welfare receipt, unemployment, and mental health problems ('SUM').

The risks of ending up in any of the clusters that involved unemployment, i.e., ' $U$ ', 'SU', and 'SUM', decreased with increasing age. The pattern was less clear for clusters characterised by more social welfare receipt ('S') or combinations of more social welfare receipt and mental health problems ('SM'), where the youngest age group had the lowest risk in comparison to all other groups. Moreover, the risk of having had comparably less education and more mental health problems ('eM') increased by age.

Having immigrant status was associated with an increased risk of being in all other clusters than the 'Average' cluster, and the cluster characterized by less education and more mental health problems ('eM'). The association was especially strong for the 
clusters characterized by social welfare receipt and unemployment ('SU'), and social welfare receipt and mental health problems ('SM').

Being unmarried, divorced or widowed, rather than married, were associated with an increased risk of being in all other clusters than the 'Average' cluster.

As is true for virtually all empirical studies, the results from this study should be interpreted with caution. The indicators of disadvantages used in this study represent a limited selection of the full range of disadvantages that occur in society. Some of these disadvantages are inherently difficult to assess using administrative registries (e.g., social isolation, hazardous working conditions, sub-clinical health problems), while information on other disadvantages were not available to us at this time (e.g., mental health problems treated in outpatient care, exposure to crime, neighbourhood deprivation). This means that we, most likely, underestimate the true prevalence of coexisting disadvantages in the population. Then again, the indicators used in this study encompass a range of widely recognised, and objectively measured disadvantages. By using these indicators, we effectively circumvent the problems that follows from subjective assessments.

The indicators used are also crude, which means that there is likely to be substantial degrees of unmeasured disadvantages in the population. This may be especially true for the indicator of mental health problems. As this indicator is based on hospitalizations due to mental health problems, it only identifies those with the most severe mental health problems. As most mental health problems do not warrant hospitalization, this may bias the results. First, the indicator substantially underestimate the prevalence of mental health problems in the population. Second, if less severe forms of mental patterns are socially patterned in the same way as those detected by the indicator, the observed associations between mental health problems, the other disadvantages, and the sociodemographic characteristics are likely to be underestimated.

Additionally, the study population is limited to the working-age population, excluding young adults below the age of 30 and individuals over the age of 60 . This means that the findings cannot be generalized beyond these age groups, especially since some of the indicators do not apply to other life stages.

Another limitation of the study stems from the use of LCA to identify meaningful clusters of individuals, characterized by specific configurations of disadvantages. As a part of this process, the researcher needs to make several judgments along the way, such as deciding on the number of clusters and how these should be labelled. Although there are several indicators of model fit that may guide these decisions, there is still an element of uncertainty. Moreover, these model-based clusters do not always provide a meaningful picture of reality. On the other hand, LCA offers a flexible approach to studying disadvantages, as it permits the use of variables that are not dichotomous. Moreover, the clusters are not predefined by the researcher, but determined by the latent structure of the data.

The current study applied a so-called 'classify-and-analyze' or 'classic three-step' approach, where latent class analysis was conducted and used to assign individuals into identified clusters, after which the clusters were used as outcomes in a multinomial regression analysis. Hence, a combination of person-oriented and variable-oriented methods. There are some disadvantages of this approach (Asparouhov and Muthén 2013; Bolck et al. 2004; Feingold et al. 2014; Vermunt 2010). According to results from simulation studies, but also from examples using real (small sample) data, our classic three-step approach may to some extent underestimate the associations of sociodemographic characteristics and latent classes compared with a modified three-step approach where all steps are performed within the same empirical model. We also note that a key rationale for using the modified approach is that its standard errors are more conservative since they are adjusted for classification 
Table 3 Cluster membership by sex, age group, immigrant status, and marital status

\begin{tabular}{|c|c|c|c|c|c|c|c|}
\hline \multirow{2}{*}{\begin{tabular}{l} 
Covariates\} $\\
{\text { cluster }}$ & 'Average' & ' $U$ ' & 'eM' & 'SU' & 'SM' & ' $\mathrm{S}$ ' & 'SUM' \\
\hline & $\begin{array}{l}\text { RRR } \\
(95 \% \mathrm{CI})\end{array}$ & $\begin{array}{l}\text { RRR } \\
(95 \% \text { CI })\end{array}$ & $\begin{array}{l}\text { RRR } \\
(95 \% \mathrm{CI})\end{array}$ & $\begin{array}{l}\text { RRR } \\
(95 \% \mathrm{CI})\end{array}$ & $\begin{array}{l}\text { RRR } \\
(95 \% \mathrm{CI})\end{array}$ & $\begin{array}{l}\text { RRR } \\
(95 \% \mathrm{CI})\end{array}$ & $\begin{array}{l}\text { RRR } \\
(95 \% \mathrm{CI})\end{array}$ \\
\hline \multicolumn{8}{|l|}{ Sex } \\
\hline Man (ref.) & 1.00 & 1.00 & 1.00 & 1.00 & 1.00 & 1.00 & 1.00 \\
\hline Woman & 1.00 & $\begin{array}{l}1.15 \\
(1.15-1.17)\end{array}$ & $\begin{array}{l}0.75 \\
(0.71-0.78)\end{array}$ & $\begin{array}{l}0.97 \\
(0.96-0.98)\end{array}$ & $\begin{array}{l}1.44 \\
(1.42-1.47)\end{array}$ & $\begin{array}{l}1.27 \\
(1.26-1.29)\end{array}$ & $\begin{array}{l}0.48 \\
(0.45-0.52)\end{array}$ \\
\hline \multicolumn{8}{|l|}{ Age group } \\
\hline $\begin{array}{l}\text { Age } 30-35 \\
\text { (ref.) }\end{array}$ & 1.00 & 1.00 & 1.00 & 1.00 & 1.00 & 1.00 & 1.00 \\
\hline Age $36-40$ & 1.00 & $\begin{array}{l}0.81 \\
(0.80-0.82)\end{array}$ & $\begin{array}{l}1.59 \\
(1.48-1.72)\end{array}$ & $\begin{array}{l}1.00 \\
(0.99-1.02)\end{array}$ & $\begin{array}{l}1.46 \\
(1.43-1.50)\end{array}$ & $\begin{array}{l}1.45 \\
(1.42-1.48)\end{array}$ & $\begin{array}{l}1.01 \\
(0.93-1.10)\end{array}$ \\
\hline Age $41-45$ & 1.00 & $\begin{array}{l}0.65 \\
(0.64-0.65)\end{array}$ & $\begin{array}{l}2.49 \\
(2.32-2.68)\end{array}$ & $\begin{array}{l}0.79 \\
(0.77-0.80)\end{array}$ & $\begin{array}{l}1.63 \\
(1.59-1.68)\end{array}$ & $\begin{array}{l}1.79 \\
(1.75-1.48)\end{array}$ & $\begin{array}{l}0.78 \\
(0.71-0.86)\end{array}$ \\
\hline Age $46-50$ & 1.00 & $\begin{array}{l}0.55 \\
(0.55-0.56)\end{array}$ & $\begin{array}{l}3.03 \\
(2.82-3.25)\end{array}$ & $\begin{array}{l}0.50 \\
(0.49-0.51)\end{array}$ & $\begin{array}{l}1.32 \\
(1.29-1.35)\end{array}$ & $\begin{array}{l}1.59 \\
(1.56-1.62)\end{array}$ & $\begin{array}{l}0.41 \\
(0.37-0.46)\end{array}$ \\
\hline \multicolumn{8}{|l|}{$\begin{array}{l}\text { Immigrant } \\
\text { status }\end{array}$} \\
\hline No (ref.) & 1.00 & 1.00 & 1.00 & 1.00 & 1.00 & 1.00 & 1.00 \\
\hline Yes & 1.00 & $\begin{array}{l}3.44 \\
(3.39-3.49)\end{array}$ & $\begin{array}{l}0.88 \\
(0.71-1.09)\end{array}$ & $\begin{array}{l}20.1 \\
(19.8-20.5)\end{array}$ & $\begin{array}{l}12.7 \\
(12.4-13.0)\end{array}$ & $\begin{array}{l}3.18 \\
(3.09-3.28)\end{array}$ & $\begin{array}{l}4.22 \\
(3.67-4.84)\end{array}$ \\
\hline \multicolumn{8}{|l|}{ Marital status } \\
\hline $\begin{array}{l}\text { Married } \\
\text { (ref.) }\end{array}$ & 1.00 & 1.00 & 1.00 & 1.00 & 1.00 & 1.00 & 1.00 \\
\hline Unmarried & & $\begin{array}{l}1.45 \\
(1.44-1.46)\end{array}$ & $\begin{array}{l}3.58 \\
(3.39-3.78)\end{array}$ & $\begin{array}{l}1.69 \\
(0.67-1.72)\end{array}$ & $\begin{array}{l}1.75 \\
(1.72-1.79)\end{array}$ & $\begin{array}{l}1.17 \\
(1.15-1.19)\end{array}$ & $\begin{array}{l}4.15 \\
(3.77-4.57)\end{array}$ \\
\hline Divorced & 1.00 & $\begin{array}{l}1.95 \\
(1.93-1.97)\end{array}$ & $\begin{array}{l}2.84 \\
(2.63-3.07)\end{array}$ & $\begin{array}{l}4.70 \\
(4.62-4.78)\end{array}$ & $\begin{array}{l}4.14 \\
(2.05-4.23)\end{array}$ & $\begin{array}{l}2.61 \\
(2.56-2.66)\end{array}$ & $\begin{array}{l}11.4 \\
(10.3-12.6)\end{array}$ \\
\hline $\begin{array}{l}\text { Widow/wid- } \\
\text { ower }\end{array}$ & 1.00 & $\begin{array}{l}1.40 \\
(1.34-1.47)\end{array}$ & $\begin{array}{l}3.21 \\
(2.47-4.17)\end{array}$ & $\begin{array}{l}2.35 \\
(2.16-2.55)\end{array}$ & $\begin{array}{l}2.50 \\
(2.28-2.74)\end{array}$ & $\begin{array}{l}1.55 \\
(1.42-1.68)\end{array}$ & $\begin{array}{l}5.56 \\
(3.43-9.03)\end{array}$ \\
\hline Unclassified & 1.00 & $\begin{array}{l}0.75 \\
(0.71-0.79)\end{array}$ & $\begin{array}{l}1.16 \\
(0.54-2.51)\end{array}$ & $\begin{array}{l}1.26 \\
(1.20-1.33)\end{array}$ & $\begin{array}{l}1.46 \\
(1.37-1.57)\end{array}$ & $\begin{array}{l}0.64 \\
(0.57-0.72)\end{array}$ & $\begin{array}{l}2.03 \\
(1.32-3.14)\end{array}$ \\
\hline
\end{tabular}}
\end{tabular}

Results from multinomial logistic regression analysis $(n=2,439,896)$

Intercepts suppressed. Estimates are mutually adjusted

$R R R$ relative risk ratio, $C I$ confidence interval

error. As a consequence, statistically significant associations may be statistically non-significant when classification error are accounted for (particularly when the sample size is small). For the purposes of this study, however, it seems safe to assume that our reported associations between sociodemographic variables and latent classes are conservative estimates. Due to our massive sample size ( $\mathrm{n}>2.4$ million), issues related to statistical significance are less sensitive when compared to analyses of smaller samples. Taken together, it is unlikely that the modified approach would alter the conclusions reached in this study.

This study is, to our knowledge, the first that have used LCA to map out coexisting disadvantage across life domains in an entire population. Compared to prior survey approaches, a major advantage with our massive sample size is that it becomes possible to identify relatively small high-risk sub-groups of the population. Since our person-centred approach moreover identify clusters of disadvantage which describe individuals rather 
than scores on variables, the conclusions reached in this study may also be more relevant for social welfare policy and practice audiences (see the "Implications for Policy and Research" section for further elaboration on this point).

Another strength of this study stem from the coverage of the administrative registries used. Prior empirical research into coexisting disadvantages and analogous concepts has typically been based on survey samples (Bask 2016; Burchardt et al. 2002; Tham 1994). While such approaches certainly have their merits, survey researchers are increasingly unable to get people to respond to surveys. Over the past decades, the nonresponse rates in survey research have risen in many countries (de Heer 1999; Groves 2006), including Sweden (Andersson and Fredriksson 2010; Boström 2010). Cooperation rates in the Swedish Level of Living Survey 1968-2010, for example, have gradually decreased: $91 \%$ (1968), 85\% (1974), 82\% (1981), 79\% (1991), 77\% (2000), and 62\% (2010) (Swedish Institute for Social Research 2015). This is troublesome, as nonresponse tends to be systematic; commonly reflecting higher nonresponse rates among individuals who are disadvantaged socioeconomically and have worse health (LindénBoström and Persson 2012; Ekholm et al. 2010). This can lead to biased research (Groves and Peytcheva 2008), which in turn may bias decision-making in social welfare policy.

The main conclusions drawn in the current study-i.e. that coexisting disadvantages do occur, albeit in a limited part of the population — are in line with previous studies using LCA on Swedish data to examine coexisting disadvantages (e.g. Almquist 2015; Almquist and Brännström 2013, 2014; Bask 2011; Halleröd and Larsson 2008). The studies by Almquist and Brännström also used register data to target the same welfare problems as this study (educational attainment, social welfare receipt, unemployment, and mental health), but they were based on slightly varying samples of only one birth cohort (born in 1953 in Stockholm, Sweden). These studies found one cluster characterised by average levels of all welfare problems, with a tendency for higher levels of educational attainment, and three clusters characterised by single or multiple welfare problems. The proportion of individuals with coexisting disadvantages varied between 6 and 19\%, placing the approximately $7 \%$ found in the current study within that interval. Sex patterns were not examined per se (only adjusted for) and age was not relevant since everyone belonged to the same birth cohort. The other two studies listed above were both based on the Swedish Survey of Living Conditions: Bask studied the clustering of chronic unemployment, economic problems, health problems, experiences of threat of violence, lack of a close friend, and sleeping problems, whereas Halleröd and Larsson included unemployment, economic vulnerability, health problems, loneliness, and anxiety as measures of welfare problems. While this makes any direct comparison with the current study difficult, it could still be pointed out that both studies found that women were more likely to be exposed to coexisting disadvantages and that the age differences were unclear and/or small.

\subsection{Implications for Policy and Research}

On basis of the results of the current study, it appears as if an abatement of the link between unemployment and other disadvantages such as mental health problems could potentially reduce the prevalence of coexisting disadvantages among men. The stronger co-occurrence of social welfare receipt and mental health problems among women suggests that either women are more vulnerable to both disadvantages independent of each other, or that financial strain may be a more potent psychological stressor for them, compared to men. Since the rates of social welfare receipt are much higher among lone mothers (Statistics Sweden 2014a, b), specific efforts could be directed toward increasing the flexibility of child care services and introducing other types of support system (Whitehead 
et al. 2000). Interestingly, this cluster was not disadvantaged in terms of full-time unemployment, suggesting that these women's financial difficulties are more likely to be a result of part-time work and/or low-wage occupations. In that case, the quality of work-in terms of e.g. occupational health hazards and stressful working conditions-for women (and particularly lone mothers) may need to be reviewed (Whitehead et al. 2000).

The results also showed that those who migrated to Sweden 1990-1997 had a substantially higher risk of coexisting disadvantages than those who were born in Sweden or migrated to Sweden earlier. This was especially true for the clusters that were characterized by combinations including social welfare recipiency and unemployment. These results underscore the importance of immigrants' precarious position on the labour market for their risk of coexisting disadvantages. Similarly, the results show that divorced individuals are substantially more likely to be in these clusters, rather than in the 'Average' cluster, when compared to married individuals. Future research should examine the mechanisms behind this apparent vulnerability.

Monitoring and evaluating represent central tenets in evidence-based policy making (Brownson et al. 2009; Nutley et al. 2007). In times when survey researchers are increasingly unable to get people to respond to surveys, and thereby introducing biased decision-making in social welfare policy and practice, we need to look for alternative ways to monitor patterns and trends of coexisting disadvantages in the population and evaluating policy efforts aiming at reducing its prevalence. This study shows that combinations of person-centred and variable-centred analyses of register-based indicators can play a part when developing effective systems for policy surveillance.

Needless to say, more research is needed in order to fully grasp the causal processes that lead to the accumulation and social patterning of coexisting disadvantages in a given population. Based on our findings, and our reading of the literature, we would suggest that there are two venues of future research that may prove especially rewarding. First, little is known about how different patterns of coexisting disadvantages develop throughout the life course of individuals, from childhood to old age. Secondly, future studies should further examine the sources of individual and social disparities in the probability of coexisting disadvantages, e.g., by social class, ethnicity, personality characteristics, and cognitive abilities.

Acknowledgements This work was supported by the Swedish Research Council for Health, Working Life and Welfare (Grant No. 2012-0201).

Open Access This article is distributed under the terms of the Creative Commons Attribution 4.0 International License (http://creativecommons.org/licenses/by/4.0/), which permits unrestricted use, distribution, and reproduction in any medium, provided you give appropriate credit to the original author(s) and the source, provide a link to the Creative Commons license, and indicate if changes were made.

\section{Appendix}

See Fig. 2. 

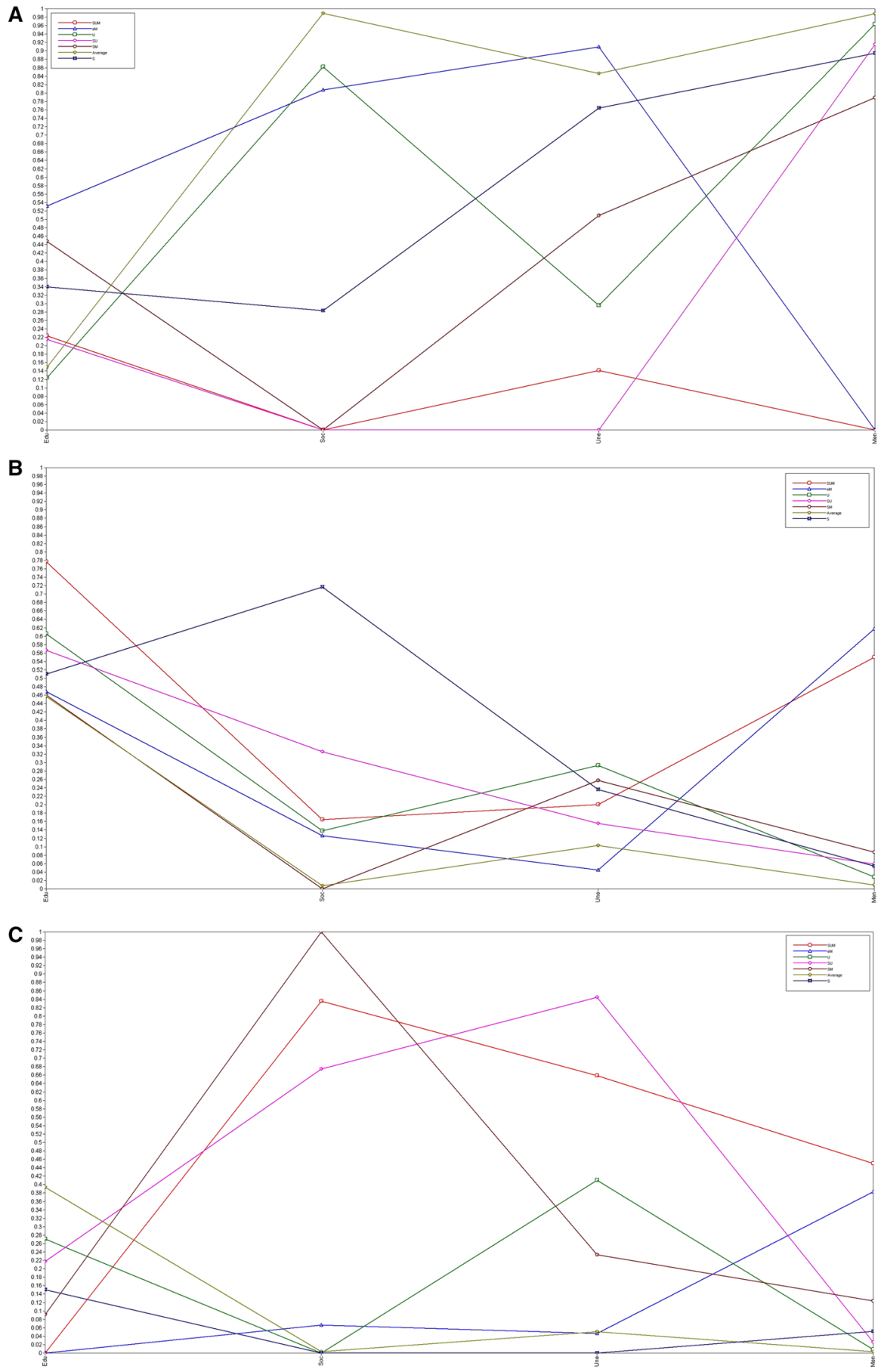
4 Fig. 2 a Estimated probabilities of Category 1 of the indicators (Educational attainment= 'Compulsory', Social welfare receipt $=$ ' 0 years', Unemployment $=$ ' 0 years', Mental health problems $=$ ' 0 discharges' $)$ $(\mathrm{n}=2,439,896)$. b Estimated probabilities of Category 2 of the indicators $($ Educational attainment $=$ 'Upper secondary', Social welfare receipt $=$ ' $1-2$ years', Unemployment $=$ ' $1-2$ years', Mental health problems $={ }^{\prime} 1-2$ discharges' $)(n=2,439,896)$. c Estimated probabilities of Category 3 of the indicators (Educational attainment $=$ 'University, Social welfare receipt $=$ ' 3 or more years', Unemployment $=$ ' 3 or more years', Mental health problems $=$ ' 3 or more discharges' $)(n=2,439,896)$

\section{References}

Almquist, Y. B. (2015). Childhood origins and adult destinations: The impact of childhood living conditions on coexisting disadvantages in adulthood. International Journal of Social Welfare. https://doi. org/10.1111/ijsw.12178.

Almquist, Y. B., \& Brännström, L. (2013). Childhood friendships and the clustering of adverse circumstances in adulthood. A longitudinal study of a Stockholm cohort. Longitudinal and Life Course Studies, 4(3), 180-195.

Almquist, Y. B., \& Brännström, L. (2014). Childhood peer status and the clustering of social, economic, and health-related circumstances in adulthood. Social Science and Medicine, 105, 67-75.

Andersson, E., \& Fredriksson, K. (2010). Arbetskraftsundersökningarna (AKU) 2008 AM0401 [Labour Force Surveys (LFS) 2008 AM0401]. Örebro: Statistiska centralbyrån [Statistics Sweden].

Asparouhov, T., \& Muthén, B. (2013). Auxiliary variables in mixture modeling: 3-step approaches using Mplus. Mplus Web Notes: No. 15. Retrievable from www.statmodel.com.

Bask, M. (2011). Cumulative disadvantage and connections between welfare problems. Social Indicators Research, 103, 443-464.

Bask, M. (2016). Accumulation and persistence of welfare problems over time. Social Indicators Research, 125(3), 757-770.

Bolck, A., Croon, M., \& Hagenaars, J. (2004). Estimating latent structure models with categorical variables: One-step versus three-step estimators. Political Analysis, 12(1), 3-27.

Boström, G. (2010). Vad betyder bortfallet för resultatet i folkhälsoenkäter? [The impact of non-response bias in public health surveys]. Östersund: Statens folkhälsoinstitut.

Brownson, R. C., Chriqui, J. F., \& Stamatakis, K. A. (2009). Understanding evidence-based public health policy. American Journal of Public Health, 99(9), 1576-1583.

Burchardt, T., Le Grand, J., \& Piachaud, D. (2002). Degrees of exclusion: Developing a dynamic, multidimensional measure. In J. Hills, J. le Grand, \& D. Piachaud (Eds.), Understanding social exclusion (pp. 30-43). New York: Oxford University Press.

Butterworth, P. (2003). Multiple and severe disadvantage among lone mothers recieving income support. Family Matters, 64, 22-29.

Danziger, S. K., Kalil, A., \& Anderson, N. J. (2000). Human capital, physical health, and mental health of welfare recipients: Co-occurence and correlates. Journal of Social Issues, 56(4), 635-654.

de Heer, W. (1999). International response trends: Results of an international survey. Journal of Official Statistics, 15(2), 129-142.

Duffy, K. (1995). Social exclusion and human dignity in Europe. Strasbourg: Council of Europe.

Ekholm, O., Gundgaard, J., Rasmussen, N. K. R., \& Hansen, E. H. (2010). The effect of health, socioeconomic position, and mode of data collection on non-response in health interview surveys. Scandinavian Journal of Public Health, 38(7), 699-706.

Eriksson, S. (2011). Utrikes födda på den svenska arbetsmarknaden [Foreign born on the Swedish labour market]. Appendix to Långtidsutredningen 2011. Stockholm: Elanders Sverige AB.

Esping-Andersen, G., \& Unies, N. (2000). Social indicators and welfare monitoring. Geneva: United Nations Research Institute for Social Development.

European Commission. (2010). Europe 2020: A strategy for smart, sustainable and inclusive growth: Communication from the commission. Brussels: Publications Office of the European Union.

Feingold, A., Tiberio, S. S., \& Capaldi, D. M. (2014). New approaches for examining associations with latent categorical variables: Applications to substance abuse and aggression. Psychology of Addictive Behaviors, 28(1), 257.

Ferrarini, T., Nelson, K., \& Sjöberg, O. (2010). Multipla välfärdsproblem [Multiple welfare problems] Social Rapport 2010 [Social Report 2010] (pp. 128-148). Stockholm: Socialstyrelsen [National Board of Health and Welfare]. 
Fritzell, J., Gähler, M., \& Nermo, M. (2007). Vad hände med 1990-talets stora förlorargrupper? Välfärd och ofärd under 2000-talet [What happened to the disadvantaged groups of the 1990s? Welfare and disadvantage during the first years of the new millennium]. Socialvetenskaplig tidskrift, 2-3, 110-133.

Fritzell, J. \& Lundberg, O. (2000). Ofärdens ackumulering och samvariation [The accumulation and covariation of illfare]. Delrapport från Kommittén Välfärdsbokslut [Interim report by the Welfare Commission]. SOU 2000:41. Stockholm: Fritzes.

Gilliver, S. C., Sundquist, J., Li, X., \& Sundquist, K. (2014). Recent research on the mental health of immigrants to Sweden: A literature review. European Journal of Public Health, 24(Suppl. 1), 72-79.

Groves, R. M. (2006). Nonresponse rates and nonresponse bias in household surveys. Public Opinion Quarterly, 70(5), 646-675.

Groves, R. M., \& Peytcheva, E. (2008). The impact of nonresponse rates on nonresponse bias. A metaanalysis. Public Opinion Quarterly, 72(2), 167-189.

Halleröd, B., \& Bask, M. (2008). Accumulation of welfare problems in a longitudinal perspective. Social Indicators Research, 88, 311-327.

Halleröd, B., \& Larsson, D. (2008). Poverty, welfare problems and social exclusion. International Journal of Social Welfare, 17(1), 15-25.

Heap, J., Lennartsson, C., \& Thorslund, M. (2013). Coexisting disadvantages across the adult age span: A comparison of older and younger age groups in the Swedish welfare state. International Journal of Social Welfare, 22(2), 130-140.

Klasen, S. (2001). Social exclusion, children and education. Implications of a rights-based approach. European Societies, 3(4), 413-445.

Korpi, T., Nelson, K., \& Stenberg, S.-A. (2007). The accumulation of social problems 1974-2000 (Chapter 4). International Journal of Social Welfare, 16, S91-S104.

Kuha, J. (2004). AIC and BIC. Comparisons of assumptions and performance. Sociological Methods Research, 33(2), 188-229.

Lindén-Boström, M., \& Persson, C. (2012). A selective follow-up study on a public health survey. European Journal of Public Health, 23(1), 152-157.

Lindström, M., \& Rosvall, M. (2012). Marital status, social capital, economic stress, and mental health: A population based study. The Social Science Journal, 49(3), 339-342.

Long, J. S., \& Freese, J. (2006). Regression models for categorical dependent variables using Stata. College Station, Texas: StataCorp LP.

Masyn, K. E. (2013). Latent class analysis and finite mixture modeling. In T. D. Little (Ed.), The Oxford handbook of quantitative methods: Statistical analysis (Vol. 2, pp. 551-611). New York: Oxford University Press.

Muthen, B., \& Muthen, L. K. (2000). Integrating person-centered and variable-centered analyses: Growth mixture modeling with latent trajectory classes. Alcoholism: Clinical and Experimental Research, 24(6), 882-891.

Nutley, S. M., Walter, I., \& Davies, H. T. (2007). Using evidence: How research can inform public services. Bristol: Policy Press.

Nylund, K. L., Asparouhov, T., \& Muthén, B. O. (2007). Deciding on the number of classes in latent class analysis and growth mixture modeling: A Monte Carlo simulation study. Structural Equation Modeling: A Multidisciplinary Journal, 14(4), 535-569.

Raftery, A. E. (1995). Bayesian model selection in social research. Sociological Methodology, 25, 111-164.

Schleicher, A. (2007). The economics of knowledge: Why education is key for Europe's success. Educational Studies, 1, 28-43.

Statistics Sweden. (2014a). Educational background among foreign born persons. Education Report 2014:6. Örebro: Statistics Sweden.

Statistics Sweden. (2014b). Women and men in Sweden 2014. Facts and figures. Örebro: Statistics Sweden.

Statistics Sweden. (2016). Biståndsmottagare efter region, ålder, kön och år [Social assistance recipient by region, age, gender, and year]. Electronic resource, retrieved on 2016-06-15, from http://www. statistikdatabasen.scb.se/sq/15345.

Statistics Sweden. (2018). Folkmängd efter ålder, kön och år [Population by age, sex and year]. Electronic resource, retrieved on 2018-07-11, from www.statistikdatabasen.scb.se/.

Stiglitz, J. E., Sen, A., \& Fitoussi, J. P. (2010). Report by the commission on the measurement of economic performance and social progress. Paris: Commission on the Measurement of Economic Performance and Social Progress.

Swedish Institute for Social Research. (2015). The Swedish Level of Living Survey (LNU). Electronic resource, retrieved on 2016-06-15, from http://www.sofi.su.se/forskning/tre-forskningsavdelningar/lnu. 
Tham, H. (1994). Ökar marginaliseringen i Sverige? [Is marginalisation increasing in Sweden?] Kriminologiska institutionen, Stockholms universitet.

The National Board of Health and Welfare. (2013). Social assistance: 2012. County and Municipal expenditures. Stockholm: National Board of Health and Welfare.

The National Board of Health and Welfare. (2016). Statistikdatabas för diagnoser $i$ sluten vård. [Statistics database for diagnoses in inpatient care] Electronic resource, retrieved on 2016-06-15, from http:// www.socialstyrelsen.se/statistik/statistikdatabas/diagnoserislutenvard.

Tsakloglou, P., \& Papadopoulos, F. (2002). Aggregate level and determining factors of social exclusion in twelve European countries. Journal of European Social Policy, 12(3), 211-225.

Vermunt, J. K. (2010). Latent class modeling with covariates: Two improved three-step approaches. Political Analysis, 18(4), 450-469.

Walzer, M. (1983). Spheres of Justice: A Defense of Pluralism and Equality. New York: Basic Books.

Whelan, C. T., \& Maître, B. (2005). Vulnerability and multiple deprivation perspectives on economic exclusion in Europe: A latent class analysis. European Societies, 7(3), 423-450.

Whitehead, M., Burström, B., \& Diderichsen, F. (2000). Social policies and the pathways to inequalities in health: A comparative analysis of lone mothers in Britain and Sweden. Social Science and Medicine, 50(2), 255-270. 